\title{
Analysis of the old mortars and proposals for the conservation of the archeological site of Logos-Edessa
}

\author{
M. A. Stefanidou \& I. Papayianni \\ Department of Civil Engineering, Aristotle University, Thessaloniki, \\ Greece
}

\begin{abstract}
The site of Logos covers an area of almost $20.000 \mathrm{~m}^{2}$ and contains city walls, roads, ruins of houses and warehouses. The building materials used were local stone and mortars. Nowadays, parts of the masonry suffer from demolition and the main reasons for decay seem to be frost, loose joints and bio-deterioration.

In the present work the analysis of the building materials is presented. The stone is travertine, a porous nature material, presenting a compressive strength of $1.2 \mathrm{MPa}$ and a porosity up to $18 \%$. As regards the mortars, two types were used for the construction: a hydraulic one containing lime and pozzolanic material and a second type based on clay.

Based on the results derived from the analysis of the authentic mortars, new compatible ones were proposed emphasizing the usage of local, low-cost materials that are friendly to the environment.
\end{abstract}

Keywords: travertine, mortar, compatible repair materials.

\section{Introduction}

The archeological site of Logos near the modern town of Edessa is a part of the ancient city located in central Macedonia, Greece. The history of the ancient city starts from the Hellenistic period and continues until the Byzantine era. The place was a passage connecting the flat with the highlands of Macedonia (Greek Ministry of Culture [1]). The life of the city was closely related to water as the river Edesseos has formed the landscape on which the city was built and also covered a part of the city with a thick layer of sediments after its evacuation. The river was probably the origin of the raw materials used for construction purposes. 
In the present time, the problem of conservation of ruins exposed to open air has different aspects (Mamillan [2]). To conserve these materials, acquires knowledge of their nature and behaviour under extreme environmental conditions. As soon as this knowledge is gained, the next step is to design new repair mortars that can work well together with the authentic materials and secure the longevity of the structure (Schafer and Hilsdorf [3], vonKonow [4]). The methodology that is applied in the Laboratory of Building materials for 15 years now has as principal the analysis of old authentic building materials in terms of microstructure, chemical, physical and mechanical characteristics (Papayianni $[5,6])$. In order to record those characteristics an adequate amount of samples is required during sampling procedure.

In the case of Logos, mortar samples were in priority as joints were loose and in some cases they were absent causing problems to the stability of the structure.

During sampling, representative samples of two different types of mortars based on the colour difference were taken as well as a big piece of structural stone.

\section{Pathology}

The main problems presented in the site of Logos are:

- Absence of joints,

- $\quad$-cracks in brick and stone samples probably due to frost action,

- -biological growth,

- $\quad$ colour alteration of stones due to black crust deposition (figure 1).

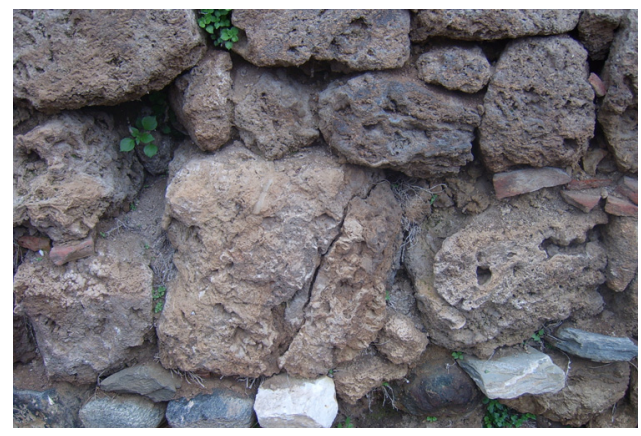

Figure 1: $\quad$ Absence of joints and cracks in stones.

\section{Experimental analysis}

The experimental analysis certified two different mortar types. The first category concerns mortars with low hydraulic character characterized by a pale brown colour. These mortars present high quantity of calcite $(46-48 \%$ b.w.). The binder is characterized as mixed type as a combination of calcite and clayish material was used due to the high percent of silica and alumina content. 
The aggregates are silica nature the granulometry of which shows that the maximum size was $8 \mathrm{~mm}$. A small percent of aggregates (estimated $5 \%$ of the whole) is fine crashed bricks $2-4 \mathrm{~mm}$. In table 1 the properties of old mortars are concluded.

The second category concerns low strength air -harden mortars of dark brown colour. The content in calcite is $40 \%$ while high percent of $\mathrm{Al}$ and $\mathrm{Si}$ is contained. Coarse, natural aggregates up to $1 \mathrm{~cm}$ were added in $1 / 2$ binder aggregate ratio.

Table 1: Characteristics of building materials at the site of Logos.

\begin{tabular}{|c|c|c|c|c|c|c|}
\hline $\begin{array}{c}\text { Type } \\
\text { of } \\
\text { mortar }\end{array}$ & $\begin{array}{c}\text { Binders } \\
\mathrm{L}=\text { lime } \\
\mathrm{S}=\text { soil }\end{array}$ & $\begin{array}{c}\text { Content in } \\
\mathrm{Ca}(\mathrm{OH})_{2} \\
\%\end{array}$ & $\begin{array}{c}\text { Total } \\
\left(\mathrm{SiO}_{2}+\mathrm{Al}_{2} \mathrm{O}_{3}\right. \\
\left.+\mathrm{Fe}_{2} \mathrm{O}_{3}\right)\end{array}$ & $\begin{array}{c}\text { Compressive } \\
\text { strength } \\
\text { MPa }\end{array}$ & $\begin{array}{c}\text { Porosity } \\
\%\end{array}$ & $\begin{array}{c}\text { binder/ } \\
\text { aggregate }\end{array}$ \\
\hline I & $\mathrm{L} / \mathrm{S}=1: 0.5$ & $46-49$ & 28.8 & $1.2-1.5$ & $18-22$ & $1: 2.5$ \\
\hline II & $\mathrm{L} / \mathrm{S}=1: 1$ & $35-40$ & 35.5 & $<1$ & $23-25$ & $1: 2$ \\
\hline stone & - & - & - & $1-1.5$ & 18 & \\
\hline
\end{tabular}

The results of the analysis show that the mortars used were based on lime and are of low strength and high porosity.

The stone is travertine and is in abundance in the area (figure 2). The mean strength is $1-1.5 \mathrm{MPa}$ while the open porosity is $18.2 \%$ and the specific gravity is 1.05. The properties of the stone are close to the mortars used and that was on the benefit of the masonry as it could work as a monolithic structure. The thickness of the joints was $1-3 \mathrm{~cm}$ depending on the stone samples used.

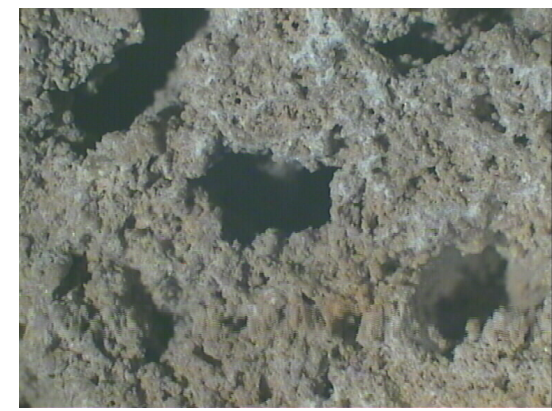

Figure 2: Travertine used in Logos (Stereoscope x8).

\section{Repair mortars}

The new repair mortars were designed based on the principal of compatibility with the existing materials. For this reason, sand and clay were taken from the site in order to test their suitability to use them as raw materials for the repair mortars. Tests concerning the granulometry, the salt content, the chemical composition and the colour of these materials were performed. The results show that the local materials were appropriate in order to use them for the mortar 
manufacture (table 2) and that had an impact to the cost benefit of the site in parallel to the harmonization of the new materials to the site.

Table 2: $\quad$ Characteristics of sand and clay from the site.

\begin{tabular}{|c|c|c|c|c|c|}
\hline & $\begin{array}{c}\text { Content in } \\
\mathrm{Ca}(\mathrm{OH})_{2} \\
\%\end{array}$ & $\begin{array}{c}\text { Total } \\
\left(\mathrm{SiO}_{2}+\mathrm{Al}_{2} \mathrm{O}_{3}+\mathrm{Fe}_{2} \mathrm{O}_{3}\right)\end{array}$ & \multicolumn{3}{|c|}{$\begin{array}{c}\text { Soluble Salts } \\
\text { \%b.w. }\end{array}$} \\
\hline & & & $\mathrm{Cl}^{-}$ & $\mathrm{NO}_{3}^{-}$ & $\mathrm{SO}_{4}{ }^{2-}$ \\
\hline Clay & 43.4 & 32.9 & 0.00 & 0.00 & $<0.01$ \\
\hline Sand & 48 & 27.5 & 0.00 & 0.01 & $<0.01$ \\
\hline
\end{tabular}

The final proposals for repair mortars were based on materials such as lime, natural pozzolana of high pozzolanic index $(7 \mathrm{MPa})$, local sand, local clay and natural coarse aggregates of silica origin. The usage of super-plastisizers free of sulfates was also suggested in order to keep the water requirements low. For the in situ application, instructions were given concerning the mixture of the materials, the water demand and the protection of the fresh mortars.

The proposal for the repair mortar was as follows:
Materials
Lime dust
parts by weight
Natural pozzolana
0.8
Local clay
0.6
Local aggregates $(0-8 \mathrm{~mm})$
0.4
Super-plasticizer
$1-2 \%$ b.w.of binder

The expected properties of the proposal mortar at the age of 28 days are:

Flexural strength: $1.0 \mathrm{MPa}$

Compressive strength: $2.5 \mathrm{MPa}$

Open porosity: $19.5 \%$

Finally the proposals were successfully completed by experienced restorers (figure 3).
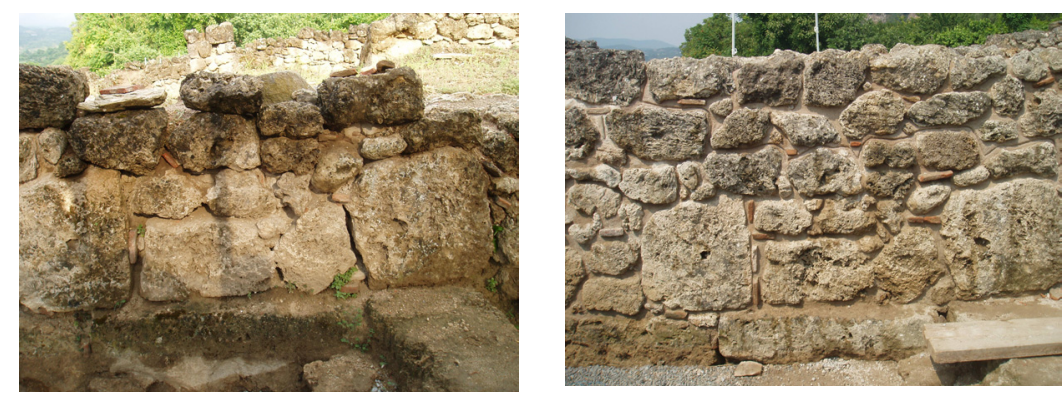

Figure 3: Structure before conservation works (left) and after the end of the works (right). 


\section{Conclusions}

In the case of Logos the scientific knowledge was successfully combined with the site experience for the benefit of the structure. In that way conservation works can be of low cost as local materials can be upgraded and also they can give good aesthetic results. Keeping in mind that ancient builders were searching in the environment of the structure for raw materials, the same principal seems that it can still work well. It is important to check the materials in the laboratory in order to avoid problems in the structure. After the end of conservation works the site should be recorded in order to check the durability of the materials and the affection of the atmosphere on the repair materials.

\section{References}

[1] Greek Ministry of Culture "Ancient Edessa" IZ Euphoria of Pre-historic and Classical Antiquities

[2] Mamillan M. "Pathology of Building materials" International Centre for the study of the Preservation and the Restoration of Cultural Property Rome, 1970

[3] Schafer J. and Hilsdorf H.K. "Ancient and new lime mortars- the correlation between their Composition, structure and properties" RILEM edited by M.J.Thiel Conservation of stone and other materials, Unesco, Paris, June 29July 1, 1993 p.p. 605-612

[4] vonKonow Theodor "Reliable restoration mortars- Requirements and composition" Proceedings $4^{\text {th }}$ International Symposium on the conservation of Monuments in the Mediterranean Rhodes 6-11 May, 1997 Edited by A. Moropoulou, F. Zezza, E. Kollias, I. Papachristodoulou vol. 3 pp.415-425

[5] Papayianni I. "A holistic way of studying mortars and bricks of ancient masonry for manufacturing compatible repair materials" Proceedings of the $4^{\text {th }}$ International Symposium on the Conservation of Monuments in the Mediterranean, Rhodes, May 6-11, 1997, pp.265-275

[6] Papayianni I. "Criteria and methodology for manufacturing compatible repair mortars and bricks" in Compatible Materials for the protection of European Cultural Heritage Proceedings Int. Conference December 1998, Athens, Pact 56 pp179-190, Editor G.Biskotin et. al. 